\title{
Research on the Design Strategy Integrated of Street Furniture from the Perspective of City Image
}

\author{
Yang Wang \\ Arts Design Department \\ Yantai Nanshan University \\ Longkou, Yantai, China \\ e-mail: nsxy2008@163.com
}

\author{
Pingqing Zhang \\ Arts Design Department \\ Yantai Nanshan University \\ Longkou, Yantai, China \\ e-mail: hit_2007@163.com
}

\begin{abstract}
With the acceleration of urbanization, great changes have occurred in city construction. The original city characteristics and memories are disappearing, and city image problems have become increasingly prominent. City administrators address much concern on the large-scale building and squares while ignoring the micro-environment of the city. This paper proposes the design strategy integrated of the street furniture given the correlation between the city image and the street furniture, and describes important role that the street furniture plays in city image construction.
\end{abstract}

Keywords-component; street furniture; design strategy integrated; city image

\section{City IMAge CONSTRUCTION UNDER THE BACKGROUND OF NEW URBANIZATION}

With the rapid development of urbanization, China's annual growth rate of city and town is 1.35 percent, and the annual growth rate of city population exceeds 20 million each year. "2012 China New Urbanization Report" published by Chinese Academy of Sciences shows that our country's urbanization rate has exceeded 50 percent. The "National new urbanization plan (2014-2020 years)" which was issued in March 2014 marks China's city development has entered a new stage of development. New urbanization is the new engine to promote economic and social development following the industrialization.

China has entered a stage of rapid development of city construction in the background of Urbanization. Each city is faced with the tasks of strengthening the city image and showing city characteristics as a part of competition between the cities. To seek advantage over other cities, every city's administrators pay close attention to constructing the largescale building and large-scale square. They think that the tallest building and the largest square in the city are key to establishing a good city image. However, they ignored the construction of the city's micro-environment as well as the cultivation of scenery of humanities. How to create a more walkable neighborhood is particularly important in terms of the large-scale city space. Since walking and communication are two basic needs of the citizens' life, street furniture plays an important role in giving them a good walking experience with the traditional road blocks, which gives intimate and comfortable space and meets the citizens' spiritual and psychological feelings. With the integrated use of little street furniture, a harmonious street landscape will be formed. This is a low input approach with high output which helps to strengthen the city image.

\section{IMPACT OF THE STREET FURNITURE ON SHAPING THE CITY IMAGE}

Kevin Lynch (American urban planner, 1918-1984) spent nearly five years studying how to interpret and recognize the city image when people are in the shuttle in the city. Kevin Lynch published "the image of the city" in 1960. He applied the theory of visual perception to study the image of the city. He believes that the image of a city is obtained needing a wide range of feelings and defines the concept of city image. Kevin Lynch thinks there are five elements contained in the city image: the street, edge, district, node and landmark. The element listed in the first place is the street, which shows that the city street is quite important for people to recognize the city as well as an important way to convey the city image.

\section{A. Impact of the Street Furniture on the Image of the City Public Space}

The forms of the city public space are diversified and complex. The image is got from people's impression after viewing the city's public space. The city public space can reflect the cultural taste of a city.. Street furniture based on the image of the city public space should implement the concept of "organic integration, people-oriented, and highlighting local characteristics". Street furniture attaches new meaning to the city public space, and enriches the quality of city streetscape environment as well as enhances the good image of the city public space.

\section{B. Impact of the Street Furniture on the Image of the City Subject Behavior}

Image of the city subject behavior makes the static and morphological elements of the city more lively and dynamic. City subject behavior regulated and guided will help strengthen the spread of the city image and promote the development of a mature civil society. How to guide or 
support the city subject behavior through the street furniture will be an important research subject. On one hand, methods of the people walking on the street will directly affect the design-oriented street furniture. On the other, street furniture will constrain or guide the behavior of civic activities. Street furniture is an important basis for reshaping the image of the city subject behavior by restricting and supporting the behavior of city street space.

\section{Impact of the Street Furniture on the Image of the City Culture}

City culture is the spiritual pillar and the emotional end of the city life. Whether a city has competitiveness and a good image to some extent can be measured by its ambience and cultural resources as well as the level of development of city culture. Good human environment of the city and unique culture constitutes a unique cultural identity of the city, and is key to city image building.

\section{IMPACT ON THE CITY IMAGE EXERTED BY THE STREET FURNITURE}

With a range of city problems arising due to the rapid urbanization, people begin to think over the problems of city construction from the perspective of changing city image. Street furniture, as an important element of the city public space, is bound to influence the strategy of city image construction.

\section{A. Impact on the City Image exerted bythe Entirety of the Street Furniture}

Street furniture systems are increasingly large and complex with the expansion of city scale. Many cities face the problem of uncoordinated and incompatibility between the street furniture and the overall city environment. Lack of integrity of design and management for the street furniture will inevitably lead to the chaos of the city image. City image building requires that the visual symbols of the city street furniture can communicate and express the harmony between the modern construction and the traditional culture. Street furniture, as the primary recognition sign for road, should be systematically designed. Therefore, the material, color, texture and scale of the street furniture should be determined based on different street environments and combined with the elements of the city image and the function of the street furniture.

\section{B. Impact on the City Image exerted by the User-Friendly Configuration of the Street Furniture}

City image aims not only to achieve the unity on the vision, but also to meet people's material and spiritual, physical and psychological requirements. The main body of the city is citizens who carry out activities on the city street. Street furniture provides the service to the people. So the design and configuration of the street furniture should be people-oriented and accord with human body engineering, behavioral psychology and humanistic care. Street furniture's utilization rate is not high. As a result, it becomes merely ornaments, which not only fail to convey a good city image, but also may become the stain of the city image building.

\section{Impact on the City Image exerted by the Context Inheritance of the Street Furniture}

How do cities highlight their unique image? Firstly, it should deal with the relationship between modernity and nationality under the background of modernization and internationalization. To seek the integration of urban regional culture and national culture and to tap the city's character and personality from traditional culture, the city administrators should shape the city image with both the modern outlook and regional characteristics.

The design inspiration of Street furniture in the modern city can be found in some elements showing the city's cultural image by extracting unique patterns, colors, materials, processes and other factors from the characteristics and culture of the city. Color, size, material and other morphological elements of Street furniture should be combined into a harmonious and unified whole, which can make the street furniture and the city context in line with the principle of respecting, protecting and perpetuating the historical and cultural values of the city.

\section{DESIGN StRATEGY INTEGRATED OF THE STREET FURNITURE}

Gestalt psychology believes that Gestalt is not the external form of an object. It is the perception of the organization as a whole which has power. Because of this Gestalt effect, those forms prone to organize, rule and unify are more easily to be identified, accepted and mastered by people.

The application of psychological theory aims to strengthen linkages and the overall format of the street furniture by reorganizing and reconciling in its shape, color, texture and other attributes. These attributes can convey information of a city, express emotion and shape the city image. So the design strategy integrated of the street furniture will become an important means to strengthen the city image.

\section{A. Design Mode Integrated of the Street Furniture}

Design mode integrated of the street furniture means using a group of combined rules to reorganize the color, texture, shape, size and other factors of the street furniture in order to form a continuous visual unity and strengthen the city image.

\section{1) Uniform color}

The colors of the street furniture are divided into two categories. One is the color of the logo which help establish the order of a city. For example, the red light means no passing of cars which the yellow light means alerting. There are also many other colors that you can choose to design and plan for the street furniture, such as green for the rubbish bins, blue for waiting rooms, etc. This part of street furniture should use the basic color system to achieve the unity so as to strengthen the city image. 


\section{2) Uniform material}

The materials used for the street furniture include stainless steel, stone, wood, concrete, plastic, etc. Different materials have different texture effects, which is an inherent property of the material. Knowing such characteristics helps determine the material and texture of the street furniture in different functional modules in order to achieve the purpose of strengthening the street image.

\section{3) Uniform form}

There are two meanings as to uniform form. First, uniform form means to effectively integrate the same type of street furniture, such as the street lights, waiting rooms, flower beds, and rubbish bins on the streets and to make them equally spaced.. Second, uniform form also means to effectively integrate different types of street furniture with efforts to reach a unified effect.

\section{4) Uniform scale}

The change of the street space environment will directly lead to scale changes of the street furniture. The street furniture may have a relatively large scale to meet its express identification. For example, the street furniture of the fast lane and the highway should necessarily be in large scale. The street furniture may have a medium scale to meet the need of pedestrians. The casual seating and sculptures in the street should accord with the pedestrian scale.

\section{B. Design Level Integrated of the Street Furniture}

Design integrated of the street furniture will properly handle the relationship between the streets, the downtown area and the whole city. street

1) Integrated design of the street furniture in single

The street is planned and designed as a whole to take into account the relationship between the street furniture and its surrounding environment. Besides, it should distinguish differences between the traditional street, landscape streets and the commercial pedestrian streets, which will have an impact on the integration of the street furniture.

\section{2) Integrated design of the street furniture in the} downtown area

The downtown area is a collection of places which have common characteristics. There will be administrative areas, commercial areas, residential areas and traditional blocks. The integrated design of the street furniture in the downtown area will be conducive to strengthening the integrity and recognition of it.

3) Integrated design of the street furniture in the whole city

The integrated design of the street furniture in the whole city is based on the integration of a number of single streets and the downtown area, which is so complex that it is necessary to consider not only the historical and cultural heritage of the traditional streets, but also the internationalization features of modern commercial district. That should be treated differently during the integrated design of the street furniture. The integrated design of the street furniture from the street, the downtown area to the whole city will play a positive role in enhancing and strengthening the city image.

\section{SUMMARY}

Design integrated of the street furniture will bring a relatively orderly image which can fully show the city's glamour and enhance people's recognition of the city.

\section{REFERENCES}

[1] Wenyuan Niu,Yijun Liu. 2012 China New Urbanization Report[M].Beijing: Cornell University Press,2012:1-3.

[2] The CPC Central Committee, the State Council.National new urbanization plan(2014-2020 years).Beijing: Xinhua News Agency,2014.3.

[3] Jifei Jiang. Double scale for the city building[J]. City Planning Forum, 2005(1):90-94.

[4] Kevin Lynch.The Image of the City[M]. MIT Press Cognition and Environment:Functioning in Uncertain World,New York,1960.

[5] Jacobs J.The death and life of great American Cities[M]. New York Random House, 1961.

[6] Urban Afairs (ed.),City Branding: Image Building and Building Images[M].Nai Uitgeversl Publishers, Roterdam, 2002.

[7] Kevin. Lynch, Managing the Sense of Region[M].The Massachusets Institute of Technology, 1976.

[8] Kevin Lynch.Reconsidering the image of the city,in City Sense and City Design[M].Cambridge,Mass:The MIT Press, 1995.

[9] PengWang.Experience Gestalt:Gestalt Psychology[M].Jinan: Shandong Education Press, 2009:76-79.

[10] Xinyu Cheng. Design and Management of Modern City street Facility[D].Harbin: Harbin Institute of Technology, 2005:32-47 